\title{
Investigating Orthorexia Nervosa With The ORTO-R in a Sample of University Students With Or Without Subthreshold Autism Spectrum: Focus On Dietary Habits and Sex Differences
}

\section{Liliana Dell'Osso}

Universita degli Studi di Pisa Dipartimento di Medicina Clinica e Sperimentale Ivan Mirko Cremone

Universita degli Studi di Pisa Dipartimento di Medicina Clinica e Sperimentale llaria Chiarantini

Universita degli Studi di Pisa Dipartimento di Medicina Clinica e Sperimentale

\section{Alessandro Arone}

Universita degli Studi di Pisa Dipartimento di Medicina Clinica e Sperimentale

\section{Danila Casagrande}

Universita degli Studi di Pisa Dipartimento di Medicina Clinica e Sperimentale

\section{Gabriele Massimetti}

Universita degli Studi di Pisa Dipartimento di Medicina Clinica e Sperimentale

\section{Claudia Carmassi}

Universita degli Studi di Pisa Dipartimento di Medicina Clinica e Sperimentale

\section{Barbara Carpita ( $\sim$ barbara.carpita1986@gmail.com )}

Universita degli Studi di Pisa Dipartimento di Medicina Clinica e Sperimentale https://orcid.org/0000-00022806-6736

\section{Research Article}

Keywords: autistic traits, orthorexia, students, eating disorders, gender differences

Posted Date: January 11th, 2022

DOl: https://doi.org/10.21203/rs.3.rs-1198646/v1

License: (a) (i) This work is licensed under a Creative Commons Attribution 4.0 International License. Read Full License 


\section{Abstract}

Purpose: The aim of the present study was to investigate the presence of ON symptoms, measured by means of the ORTO-R, in a sample of University students with or without AT, specifically focusing on evaluating the role of sex and of dietary habits in the association between $\mathrm{ON}$ and autism spectrum.

Methods: Subjects were requested to anonymously fulfil the ORTO-R and the Adult Autism Subthreshold Autism Spectrum (AdAS Spectrum) through an online form.

Results: 2140 students participated in the study. Subjects with significant AT reported significantly higher ORTO-R scores than subjects without AT. Females and subjects following a vegetarian/vegan diet reported significantly higher ORTO-R scores than males and than subjects following an omnivorous diet, respectively. Significant positive correlations were found between ORTO-R and AdAS Spectrum scores. A decision tree model, with sex, type of diet and presence of AT as independent variables and ORTO-R score as dependent variable, showed in the first step the presence of significantly higher ORTO-R scores among females than among males, and in the second step showed in both sexes the presence of higher ORTO-R scores among subjects with AT than in those without. A significant interaction of sex and presence/absence of AT was reported on ORTO-R score, with a higher increasing trend of ORTO-R score with the increase of AdAS Spectrum score among females than among males.

Conclusions: Our results further highlighted the association between AT and ON, in particular among females.

\section{Introduction}

During the last decades, in parallel with the evolution of social and cultural environment, modern psychiatry has faced the emergence of new psychopathological conditions, characterized by peculiar clinical pictures. This is the case of orthorexia nervosa (ON), a condition described for the first time by Steve Bratman in the late 1990s [1]. ON features an eating pattern mainly characterized for an abnormal fixation and obsession for a healthy style of eating (Bratman, 1997). The word "orthorexia" derives from the Greek "ortho", which means "correct / adequate", and "orexis", which means "appetite". Individuals affected by this condition usually adopt restrictive dietary habits, progressively excluding more and more foods considered unhealthy from their diet. Despite the persistence of diagnostic uncertainty for this condition, which to date is not included in the fifth edition of the Diagnostic and Statistical Manual of Mental disorders (DSM-5) [2], a wide range of possible risk factors has been proposed, such as an individual or family history of other mental disorders, previous overweight or obesity, neurotic or perfectionist personality traits. or also the presence of a high income. Other features associated with ON were the previous presence of specific dietary habits, such as veganism or vegetarianism, a high income or a high intermediate level of instruction. In addition, specific populations, such as athletes or health workers, seem to show a greater risk towards the development of ON symptoms [3][4][5][6][7][8][9]. According to previous studies, the prevalence of ON may vary depending on the kind of sample considered, ranging from $1-57.6 \%$ in the general population [3][10][11][12] and from 35-57.8\% in high-risk groups. The distribution of ON in the two sexes is still debated. Several studies reported a higher prevalence among females, although with a lower male/female ratio with respect to AN [3][5][6][13][14][15]. However, not all the studies confirmed this result [16] [17]. To date, several instruments were developed for measuring ON. The most frequently employed questionnaire in this field is the ORTO-15 [15][18], although this instrument has been increasingly criticized due 
to the lack of reliability and adherence to the ON symptoms. In particular, the ORTO-15 was developed and validated several years ago, before a more shared agreement on ON definition and features was reached in the scientific literature [19]. Only recently Rogoza and Donnini [19] proposed a revised version of the instrument, the ORTO-R, which was developed to be in line with the more updated descriptions of ON and reported promising results in the validation study.

Some authors suggested that the spreading of ON may mirror the spreading of the contemporary ideal of healthy eating, which is gradually replacing the ideal of thinness typical of the 1980s and 1990s: in this framework, ON might be considered a restrictive eating disorder in the same psychopathological spectrum of restrictive Anorexia nervosa (AN-R), with different presentations linked to environmental factors [5][20][21]. Several studies, in line with this hypothesis, highlighted the similarities between AN and ON, stressing that, despite the shift of the focus on food quality rather than food quantity, these conditions would share a common symptomatology core and would also be associated with similar personality traits, such as perfectionism or inflexibility [14][20]. On the other hand, ON has been also associated with other psychopathological dimensions, such as the obsessive-compulsive spectrum, stressing the presence of rituals, repetitive behaviours and perfectionism traits in both the disorders [4]. At the same time, increasing literature reported the presence of a possible association between AN and female phenotypes of Autism Spectrum Disorder (ASD). ASD is a neurodevelopmental disorder characterized by an impairment in social communication and interactions, narrow interests and repetitive behaviours, which shows a dramatically higher prevalence among males (while AN shows instead a great prevalence among females) [2]. Since the '70s, some authors reported a familial aggregation between AN and ASD as well as similar clinical features [14][20][22]. It was pointed out that the strict focus on food and diet and the ritualized behaviours linked to food intake typical of AN may resemble the pattern of narrow interests and repetitive behaviours of ASD more than the obsessions and compulsion of obsessive-compulsive disorder [14]. In addition to a pattern of rigid habits, inflexibility and narrow interests, the presence of deficits in socio-emotional reciprocity and alterations in theory of mind was also reported among AN patients, further stressing its symptomatological overlaps with the autism spectrum [14][23][24][25]. Several studies in the last years reported, among patients with AN, a higher prevalence of ASD [26]. The presence of subthreshold autistic traits (AT) was reported to be particularly higher among subjects with AN [14][21], although increased AT were also found in patients with Bulimia nervosa and Binge eating disorder, which were often been associated with mood disorder spectrum in the literature [14][21][27].

It should be noted that the label of "AT" is used for describing the presence of symptoms and traits similar, although sub-threshold, to those reported by subjects with ASD. In line with the spectrum model, which features a dimensional approach to psychopathology and recognizes the presence of a continuum between full-blown disorders and isolated, atypical or more nuanced symptoms [28], AT seems to be distributed in a continuum from the general to the clinical population, being particularly represented in some specific high risk groups, including subjects with other kinds of psychiatric disorders [21][29][30][31][32][33][34][35][36][37]. The similarities between AN and autism spectrum, together with the inverse prevalence of these conditions in the two sexes, led some authors to hypothesize that AN might be re-conceptualized as a female-specific phenotype of ASD [15]. The possible link between autism spectrum and AN was further supported by studies focused on female presentations of ASD, which reported that autistic-like symptoms may be underrecognized among females due to the presence of different features with respect to those typical of males. In particular, ASD females seem to report a lower impairment in social relationships, showing a higher ability to cope with the 
social environment through camouflaging strategies, although reporting more often social anxiety symptoms. Moreover, female forms of ASD would feature different kinds of restricted interests, such as spending time with animals, focusing on fictions or celebrities, or also on food and diet [15][38][39]. Despite this amount of studies about the link between autism spectrum and AN, limited research focused on evaluating the possible association between ON and AT. However, as in the case of AN, the obsession with a healthy diet, the ritualized behaviours associated with the preparation and consumption of food, with a selective and narrow interest towards diet, seems to show several overlaps with autistic-like symptomatology. Similarly, the sense of moral superiority and the intolerance towards the eating habits of other people may recall the deficits of the socioemotional reciprocity typically found in autistic patients [20]. A previous study by Carpita et al. [15] showed, in a wide University population (students as well as University workers), a greater presence of AT among subjects with ON symptoms, measured by means of the ORTO-15. Moreover, they found that being females and reporting higher AT were statistically predictive factors towards the presence of ON. While this study seems to further support the hypothesis that ON may be associated, like AN, with female presentations of the autism spectrum, the use of ORTO-15, as reported above, was criticized by previous studies.

In this framework, the aim of the present study was to investigate the presence of ON symptoms, measured by means of the ORTO-R, in a sample of University students with or without AT, specifically focusing on evaluating the role of sex and of dietary habits in the association between $\mathrm{ON}$ and autism spectrum.

\section{Methods}

\section{Participants}

All the students of University of Pisa received an e-mail invitation to participate in the survey. Subjects who agreed to participate were requested to fill out a form with socio-demographic variables and they were subsequently assessed with self-report psychometric instruments. All the procedures were conducted through an anonymous online form. Students did not receive any payment or benefit for agreeing to participate. The study was conducted in accordance with the Declaration of Helsinki and the local Ethics Committees approved all recruitment and assessment procedures. The questionnaire employed in the present work were the Adult Autism Subthreshold Spectrum (AdAS Spectrum) and the ORTO-R.

\section{AdAS Spectrum}

The Adult Autism Subthreshold Spectrum (AdAS Spectrum) is an instrument tailored to evaluate the presence of full-threshold and subthreshold autism spectrum symptoms and traits, as well as sex-specific traits, in adults with no diagnosis of intellectual disabilities and alterations in language development [40]. The questionnaire is composed of 160 items, grouped in 7 domains: Childhood/adolescence, Verbal communication, Non-verbal communication, Empathy, Inflexibility and adherence to routine, Restrictive interests and rumination, Hyperhypo reactivity to sensory input. Higher scores indicate a higher impairment in the assessed dimension. According to the validation study, the AdAS Spectrum was proven to be a reliable quantitative assessment of AT, and it was employed in several clinical and non-clinical studies [21][33][34][41][42][43][44][45]. A Spanish version has also been validated [46]. 2The instrument features also two threshold values: a cut-off score of 70, 
for identifying the presence of full-blown ASD symptoms, and a cut-off score of 43 , for identifying the presence of AT [37].

\section{ORTO-R}

ORTO-R [19] is the revised and abbreviated version of the ORTO-15 [18], a questionnaire developed to assess orthorexic features. It consists of 6 items that investigate, whether food choices are conditioned by health concerns (item 1), whether the belief that healthy food consumption improves self-esteem (item 2) or appearance (item 3), if thoughts about food have caused feelings of guilt, shame, or anxiety in the last three months (item 4), how long concerns for food take up per day (item 5), and whether food concerns affect the psychosocial functioning of the individual (item 6). Each item can be answered on a four-point scale (Always, Often, Sometimes, Never). Higher scores suggest an increased tendency towards ON. The ORTO-R was developed with the aim to overcome the flaws of the ORTO-15, which was one of the first questionnaires in this field and thus was criticized for its lack of reliability and adherence to the actual ON symptoms, while ORTO-R was tailored to be in line with the most recent descriptions and definitions of ON. According to the validation study, the ORTO-R seems to be a promising and reliable tool [19].

\section{Statistical analyses}

For the aims of the present work we compared two groups of students, splitting the sample on the basis of the presence of significant AT according to the AdAS Spectrum (AT and No AT group). In particular, students with a AdAS Spectrum score beyond the cut-off of 43 for significant AT were included in the AT group, while subjects who scored below were included in the No AT group. Student's t-tests and Chi-square tests were employed to compare sociodemographic variables and ORTO-R scores between groups. Moreover, Student's t-tests were used to compare ORTO-R scores among subjects with different sociodemographic characteristics. Pearson's correlation coefficient was calculated for investigating the presence of significant correlations between the AdAS Spectrum and the ORTO-R. We performed a decision tree model in order to identify which variables among sex, type of diet and presence of AT best predicted ORTO-R scores. This analysis allows us to examine interactions among variables and create a decision tree model, graphically representing the findings as an inverted tree. The model starts with a root node with all the cases included, and then the tree grows by choosing at each step the independent variable with the higher interaction with the dependent variable. The model also merges the categories defined by predictors when no difference is reported with respect to the dependent variable. Finally, an analysis of variance (ANOVA) with a factorial design was performed with ORTO-R as dependent variable and the presence of AT and sex as independent variables. All the analyses were conducted with SPSS, version 24 (IBM Corp., 2016).

\section{Results}

On the basis of the AdAS Spectrum cut-off, we identified 1318 subjects with AT (AT group) and 822 subjects without (no AT group). The mean age of the sample was $23.80 \pm 4.80$. The sample was composed by a total of 2140 students, 66.1\% ( $\mathrm{N}=1414)$ identified themselves as females and 33.9\% ( $\mathrm{N}=726)$ as males. Moreover, 1956 students (94.3\%) followed an omnivorous diet, while 118 students (5.7\%) were following at the time of the questionnaire a vegetarian or vegan diet. 
No significant differences were found with respect of sex and type of diet distribution between AT and No AT groups. When performing Student's t-tests, we found that subjects in the AT group showed a significantly higher ORTO-R score than the no AT group (see Table 1). Moreover, in the overall sample females reported significantly higher ORTO-R scores than males, while subjects who followed a vegetarian/vegan diet showed significantly higher ORTO-R score than those following an omnivorous diet (see Table 2).

Table 1

Comparison of sociodemographic variables and ORTO-R scores between AT and No AT group

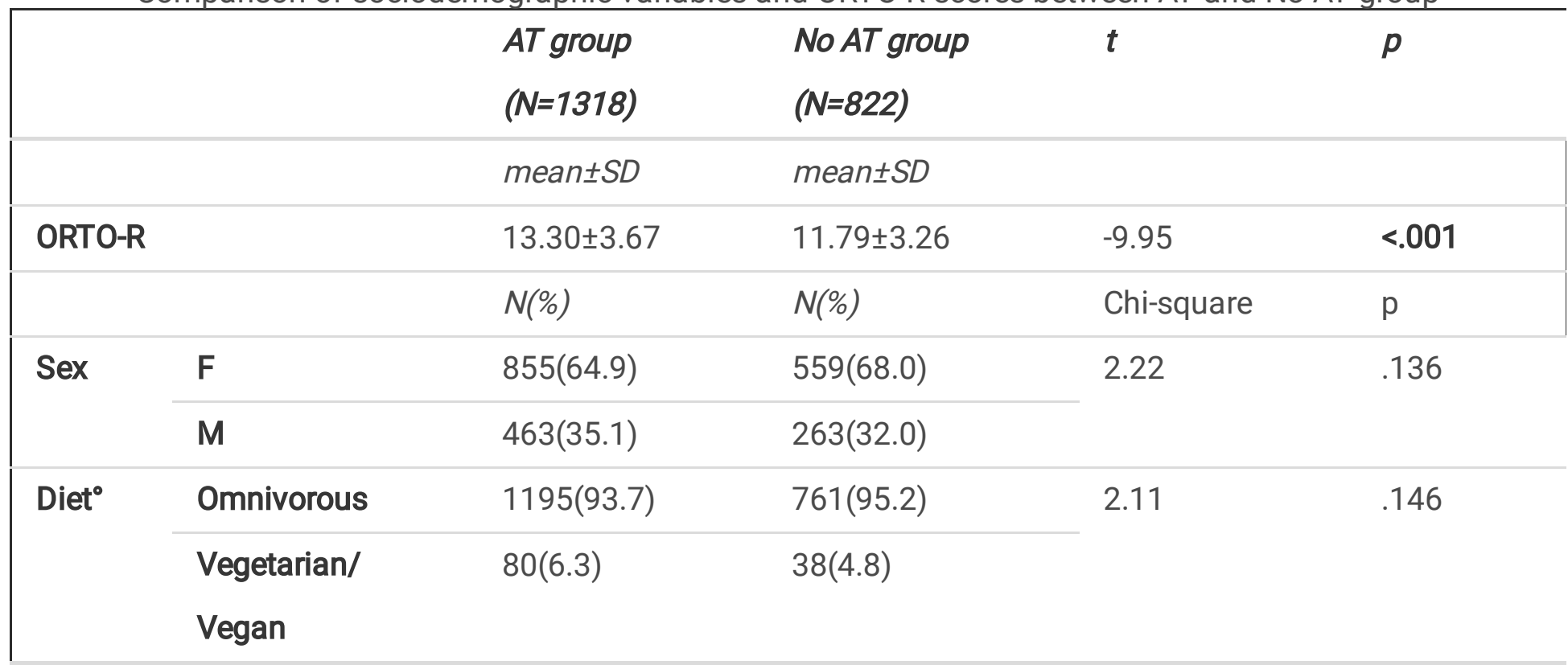

'only a subset of 2074 students reported this data

Table 2

Comparison of ORTO-R scores depending from sex and diet

\begin{tabular}{|lllllllll|}
\hline & Sex & \multicolumn{7}{c|}{ Diet } \\
\cline { 2 - 9 } & $F(N=1414)$ & $M$ & $t$ & $p$ & $\begin{array}{l}\text { Omnivorous } \\
(N=1956)\end{array}$ & $\begin{array}{l}\text { Vegetarian/ } \\
\text { Vegan } \\
(N=118)\end{array}$ & t & p \\
\hline $\begin{array}{l}\text { ORTO-R } \\
(\text { mean } \pm S D)\end{array}$ & $13.31 \pm 3.63$ & $11.57 \pm 3.24$ & -11.32 & $<.001$ & $12.63 \pm 3.59$ & $14.19 \pm 3.40$ & -4.58 & $<.001$ \\
\hline
\end{tabular}

When performing a Pearson's correlation coefficient, we also found that ORTO-R was significantly correlated with the AdAS Spectrum in both females and males, although correlation coefficients were slightly higher among females for total AdAS Spectrum and most of the domain scores (see Table 3).

Table 3. Correlations between ORTO-R and AdAS Spectrum scores among males and females 
ORTO-R

Males $\quad$ Females $(\mathrm{N}=1414)$

$(\mathrm{N}=726)$

\section{AdAS Spectrum}

\begin{tabular}{lll}
\hline Childhood/Adolescence & $.165^{\star}$ & $.210^{\star}$ \\
\hline Verbal communication & $.187^{\star}$ & $.147^{\star}$ \\
\hline Non verbal communication & $.229^{\star}$ & $.272^{\star}$ \\
\hline Empathy & $.090^{\star}$ & $.125^{\star}$ \\
\hline Inflexibility and adherence to routine & $.227^{\star}$ & $.266^{\star}$ \\
\hline Restricted interests and rumination & $.230^{\star}$ & $.244^{\star}$ \\
\hline Hyper-Hypo reactivity to sensory input & $.198^{\star}$ & $.175^{\star}$ \\
\hline AdAS Spectrum total score & $.243^{\star}$ & $.274^{\star}$
\end{tabular}

*Significant correlation, $p<.001$

Results from the decision tree model, with sex, type of diet and presence of AT as independent variables and ORTO-R score as dependent variable, showed in the first step the presence of significantly higher ORTO-R scores among females than among males. Subsequently, among both females and males, the AT group scored higher than the no AT group. No effect was found for the type of diet (See Figure 1). Finally, in order to further deepen the investigation on the effect and the interaction between the presence of AT and sex on ORTO-R scores, we performed a factorial ANOVA analysis. Results reported a significant main effect of sex and of AT on ORTO-R score: $F(1,2136)=105.79, p<.001$ and $(F 1,2136)=73.83, p<.001$ respectively. There was also a significant interaction between sex and AT on ORTO-R score: $F(1,2136)=12.06, p=.001$. In particular, we found that, although in both sexes ORTO-R scores increased with the increase of the AdAS Spectrum scores, the increasing trend was higher among females (see Table 4 and Figure 2). A similar trend was also observable when performing a Student's $t$ tests to compare ORTO-R scores between AT and No AT groups in the two sexes. In particular, while in both sexes subjects with AT showed higher ORTO-R scores than subjects without, t-test results among females showed a greater level of significance and higher t values (See Table 5). 
Table 4

Factorial ANOVA analysis with sex and presence of AT as independent variables and ORTO-R score as dependent variable

\begin{tabular}{|llllll|}
\hline Source & Type III Sum of Squares & $\mathbf{d f}$ & Mean Square & $\mathbf{F}(\mathbf{1 , 2 3 6 )}$ & $\mathbf{p}$ \\
\hline Corrected model & 2854.16 & 3 & 951.39 & 81.77 & $<.001$ \\
\hline Intercept & 270755.07 & 1 & 270755.07 & 23271.24 & $<.001$ \\
Sex & 1230.87 & 1 & 1230.87 & 105.79 & $<.001$ \\
\hline AT & 859.03 & 1 & 859.03 & 73.83 & $<.001$ \\
Sex*AT & 140.28 & 1 & 140.28 & 12.06 & .001 \\
\hline Error & 24851.82 & 2136 & 11.64 & - & - \\
\hline Total & 374265.00 & 2140 & - & - & - \\
\hline Corrected total & 27705.99 & 2139 & - & - & - \\
\hline$R$ squared=.103; Adjusted $R$ squared=.102 & & & & \\
\hline
\end{tabular}

Table 5. Comparison of ORTO-R scores between AT and no AT group among males and females

Males

$\begin{array}{lllll}\text { No AT } & \text { AT group } & t & p & \text { No AT } \\ \text { group } & (\mathrm{N}=463) & & & \text { group } \\ (\mathrm{N}=263) & & & & (\mathrm{N}=559)\end{array}$

Females

$.001 \quad 12.14 \pm 3.32$

AT group $\quad t \quad p$
$(N=855)$

ORTO-R

$($ mean $\pm S D)$

$11.04 \pm 2.98$

$11.87 \pm 3.34$

$-3.42$

$14.08 \pm 3.61 \quad-10.38$

.001

\section{Discussion}

The aim of the present study was to assess the presence of ON in a population of University students, with and without AT, with a focus on the role of diet and sex differences.

We found a significantly higher prevalence of ON symptoms in women and in subjects following a vegetarian/vegan diet. Despite some authors did not found significant sex differences in ON, or even reported a higher prevalence among men [10][11][18][47][48] ( Fidan et al., 2010; Dunn et al., 2017), our results seem in line with the several studies which instead reported a higher prevalence of ON among females [14][49][50].

Dell'Osso et al. reported a higher prevalence of ON among females and among subjects with a vegetarian/vegan diet among university students [5][6]. As previously highlighted, the increased prevalence of ON among females supported the hypothesis of a possible continuum between $\mathrm{ON}$ and AN, which might also share a similar distribution among sexes [6][14][15]. Regarding the role of diet, our results confirm previous reports from the literature, which highlighted a link between $\mathrm{ON}$, obsession for healthy eating and vegan/vegetarian dietary habits [6][14][15][40][51][52]. In particular, in a recent review from Brytek-Matera et al. [53], an association between vegetarianism and eating behaviours typical of ON was found in 11 out of the 14 
studies included, thus raising the question if vegetarianism may represent a risk factor for the development of ON. The higher prevalence of ON symptoms in subjects with AT reported in this study is in line with the higher levels of AT among subjects scoring over the threshold for ON (as measured by the ORTO-15) previously reported in a university population [15]. The similar findings reported by means of different questionnaires strengthen the validity of the association between these two conditions. Our results, further support the link between $\mathrm{ON}$ and the autism spectrum, according to the spreading hypothesis of an association between ASD and restrictive eating disorders [20][21][22][54][55][56][57]. Noticeably, patients with ASD often display restrictive eating behaviours, such as highly selective food choices or a total refusal of specific kinds of food [20][58] , a feature that may resemble the habits of orthorexic subjects. At the same time, subjects affected by ON typically show ritualized behaviours in the preparation and consumptions of food and often report a strong cognitive focus on eating habits, which recall the well-known stereotyped behaviours and interests of ASD. In addition, the feeling of moral superiority and the intolerance towards eating behaviours of other people may suggest the presence of autistic-like deficits in socio-emotional reciprocity in ON subjects [2][20].

A significant correlation was also found between ORTO-R and the AdAS Spectrum, with a tendency towards stronger correlation coefficients among females. Moreover, according to our results, there was a significant interaction of AT and sex on ON: while ORTO-R scores rose with the increase of AdAS Spectrum scores, the rising of the ORTO-R scores was higher among females. These findings, suggesting a specifically higher association between $\mathrm{ON}$ and autism spectrum among females, may be considered in line with the literature which hypothesized a link between AN and female presentations of ASD, leading to hypothesize that the overlap between autism and eating disorder spectra among females may extend also to ON [14][59]. According to this hypothesis, ON may be included in the same autism spectrum phenotype of AN and, subsequently, AN and ON might share the same autistic core which, in this case, would be expressed by an inflexible and narrow focus on eating habits, together with stereotyped and repetitive behaviours related to food and altered socioemotional reciprocity.

This study should be considered in light of several limitations. Firstly, our sample included only University students, and thus our results could not be extended to the general population. Secondly, subjects were recruited on a voluntary basis, eventually leading to selection biases in the sample.

Moreover, both the AdAS Spectrum and ORTO-R are self-reported questionnaires, and the use of this kind of instruments may lead to biases in the results due to an underestimation or an overestimation of the symptoms by the subjects. In addition, no information was available about the presence among the subjects of an actual diagnosis of ASD or of Feeding and eating disorders, or also of other comorbid mental disorders, which may have affected our results. Finally, this study featured a cross-sectional design, and subsequently it was not possible to make inferences on any cause-effect or temporal relationship regarding our findings. Further studies featuring a full-fledged clinical assessment and possibly, a longitudinal design are warranted for clarifying the relationship between $\mathrm{ON}$ and AT.

\section{Declarations}

\section{Funding}


The authors declare that no funds, grants, or other support were received during the preparation of this manuscript.

\section{Competing Interests}

The authors have no relevant financial or non-financial interests to disclose.

\section{Ethics approval}

This study was performed in line with the principles of the Declaration of Helsinki. Approval was granted by the Committee on Bioethics of the University of Pisa (Protocol number: 0072245/2019; Date: July 07, 2019).

\section{Consent to participate}

Informed consent was obtained from all individual participants included in the study.

\section{References}

1. Bratman S (1997) Health food junkie. Yoga Journal 136:42-50

2. American Psychiatric Association (2013) Diagnostic and statistical manual of mental disorders, 5th edn. APA, Washington, DC

3. Ramacciotti CE, Perrone P, Coli E, Burgalassi A, Conversano C, Massimetti G, Dell'Osso L (2011) Orthorexia nervosa in the general population. a preliminary screening using a self-administered questionnaire (ORTO15).Eat Weight Disord16(2):e127-e130. https://doi.org/10.1007/bf03325318

4. Koven NS, Abry AW (2015) The clinical basis of orthorexia nervosa: emerging perspectives. Neuropsychiatr Dis Treat 11:385-394. https://doi.org/10.2147/ndt.S61665

5. Dell'Osso L, Abelli M, Carpita B, Massimetti G, Pini S, Rivetti L, Gorrasi F, Tognetti R, Ricca V, Carmassi C (2016) Orthorexia nervosa in a sample of Italian university population. Riv Psichiatr 51(5):190-196. https://doi.org/10.1708/2476.25888

6. Dell'Osso L, Carpita B, Muti D, Cremone IM, Massimetti G, Diadema E, Gesi C, Carmassi C (2018) Prevalence and characteristics of orthorexia nervosa in a sample of university students in Italy. Eat Weight Disord 23(1):55-65. https://doi.org/10.1007/s40519-017-0460-3

7. Barnes MA, Caltabiano ML (2017) The interrelationship between orthorexia nervosa, perfectionism, body image and attachment style. Eat Weight Disord 22(1):177-184. https://doi.org/10.1007/s40519-016-0280$\mathrm{X}$

8. Scarff JR (2017) Orthorexia nervosa: an obsession with healthy eating. Fed Pract 34(6):36-39

9. McComb SE, Mills JS (2019) Orthorexia nervosa: a review of psychosocial risk factors. Appetite 140:5075. https://doi.org/10.1016/j.appet.2019.05.005

10. Dunn TM, Gibbs J, Whitney N, Starosta A (2017) Prevalence of orthorexia nervosa is less than 1\%: data from a US sample. Eat Weight Disord 22(1):185-192. https://doi.org/10.1007/s40519-016-0258-8

11. Fidan T, Ertekin V, Isikay S, Kirpinar I (2010) Prevalence of orthorexia among medical students in Erzurum, Turkey. Compr Psychiatry 51(1):49-54. https://doi.org/10.1016/j.comppsych.2009.03.001 
12. Segura-García C, Papaianni MC, Caglioti F, Procopio L, Nisticò CG, Bombardiere L, Ammendolia A, Rizza P, De Fazio P, Capranica L (2012) Orthorexia nervosa: a frequent eating disordered behavior in athletes. Eat Weight Disord 17(4):226-233. https://doi.org/10.3275/8272

13. Gramaglia C, Gambaro E, Delicato C, Marchetti M, Sarchiapone M, Ferrante D, Roncero M, Perpiñá C, BrytekMatera A, Wojtyna E, Zeppegno P (2019) Orthorexia nervosa, eating patterns and personality traits: a crosscultural comparison of Italian, Polish and Spanish university students. BMC Psychiatry 19(1):235. https://doi.org/10.1186/s12888-019-2208-2

14. Carpita B, Muti D, Cremone IM, Fagiolini A, Dell'Osso L (2020) Eating disorders and autism spectrum: links and risks. https://doi.org/10.1017/S1092852920002011. CNS Spectr 1-9

15. Carpita B, Cremone IM, Amatori G, Cappelli A, Salerni A, Massimetti G, Borgioli D, Carmassi C, Massai R, Dell'Osso L (2021) Investigating the relationship between orthorexia nervosa and autistic traits in a university population. CNS Spectr 1-8. https://doi.org/10.1017/S1092852921000420

16. Bratman S, Knight D (2000) Health food junkies: overcoming the obsession with healthful eating. Broadway Books, New York

17. Donini LM, Marsili D, Graziani MP, Imbriale M, Cannella C (2004) Orthorexia nervosa: a preliminary study with a proposal for diagnosis and an attempt to measure

18. the dimension of the phenomenon.Eat Weight Disord9(2):151-157. https://doi.org/10.1007/BF03325060

19. Donini LM, Marsili D, Graziani MP, Imbriale M, Cannella C (2005) Orthorexia nervosa: validation of a diagnosis questionnaire. Eat Weight Disord 10(2):e28-e32. https://doi.org/10.1007/BF03327537. a

20. Rogoza R, Donini LM (2021) Introducing ORTO-R: a revision of ORTO-15: Based on the re-assessment of original data. Eat Weight Disord 26(3):887-895. https://doi.org/10.1007/s40519-020-00924-5

21. Dell'Osso L, Abelli M, Carpita B, Pini S, Castellini G, Carmassi C, Ricca V (2016) Historical evolution of the concept of anorexia nervosa and relationships with orthorexia nervosa, autism, and obsessive-compulsive spectrum. Neuropsychiatr Dis Treat 12:1651-1660. https://doi.org/10.2147/ndt.S108912

22. Dell'Osso L, Carpita B, Gesi C, Cremone IM, Corsi M, Massimetti E, Muti D, Calderani E, Castellini G, Luciano M, Ricca V, Carmassi C, Maj M (2018) Subthreshold autism spectrum disorder in patients with eating disorders. Compr Psychiatry 81:66-72. https://doi.org/10.1016/j.comppsych.2017.11.007

23. Gillberg C (1983) Are autism and anorexia nervosa related? Br J Psychiatry 142:428. https://doi.org/10.1192/bjp.142.4.428b

24. Schulte-Rüther M, Mainz V, Fink GR, Herpertz-Dahlmann B, Konrad K, Karjalainen L, Råstam M, PaulsonKarlsson G, Wentz E (2012) (2019) Do autism spectrum disorder and anorexia nervosa have some eating disturbances in common? Eur Child Adolesc Psychiatry 28(1):69-78. https://doi.org/10.1007/s00787-0181188-y

25. Brown CM, Stokes MA (2020) Intersection of eating disorders and the female profile of autism. Child Adolesc Psychiatr Clin N Am 29(2):409-417. https://doi.org/10.1016/j.chc.2019.11.002

26. Huke V, Turk J, Saeidi S, Kent A, Morgan JF (2013) Autism spectrum disorders in eating disorder populations: a systematic review. Eur Eat Disord Rev 21(5):345-351. https://doi.org/10.1002/erv.2244

27. Ramacciotti CE, Paoli RA, Marcacci G, Piccinni A, Burgalassi A, Dell'Osso L, Garfinkel PE (2005) Relationship between bipolar illness and binge-eating disorders. Psychiatry Res 135(2):165-170. https://doi.org/10.1016/j.psychres.2004.04.014

Page $11 / 16$ 
28. Frank E, Cassano GB, Shear MK, Rotondo A, Dell'Osso L, Mauri M, Maser J, Grochocinski V (1998) The spectrum model: a more coherent approach to the complexity of psychiatric symptomatology. CNS Spectr 3(4):23-34. https://doi.org/10.1017/S1092852900005836

29. Baron-Cohen S, Wheelwright S, Skinner R, Martin J, Clubley E (2001) The autism-spectrum quotient (AQ): evidence from Asperger syndrome/high-functioning autism, males and females, scientists and mathematicians. J Autism Dev Disord 31(1):5-17. https://doi.org/10.1023/A:1005653411471

30. Jobe LE, White SW (2007) Loneliness, social relationships, and a broader autism phenotype in college students. Pers Individ Dif 42(8):1479-1489. https://doi.org/10.1016/j.paid.2006.10.021

31. Trevisan D, Birmingham E (2016) Examining the relationship between autistic traits and college adjustment. Autism 20(6):719-729. https://doi.org/10.1177/1362361315604530

32. Dell'Osso L, Muti D, Carpita B, Cremone IM, Bui E, Gesi C, Carmassi C (2018) The adult autism subthreshold spectrum (AdAS) model: a neurodevelopmental approach to mental disorders. Journal of Psychopathology 24:118-124

33. Dell'Osso L, Cremone IM, Carpita B, Fagiolini A, Massimetti G, Bossini L, Vita A, Barlati S, Carmassi C, Gesi C (2018) Correlates of autistic traits among patients with borderline personality disorder. Compr Psychiatry 83:7-11. https://doi.org/10.1016/j.comppsych.2018.01.002

34. Dell'Osso L, Carpita B, Muti D, Morelli V, Salarpi G, Salerni A, Scotto J, Massimetti G, Gesi C, Ballerio M, Signorelli MS, Luciano M, Politi P, Aguglia E, Carmassi C, Maj M (2019) Mood symptoms and suicidality across the autism spectrum. Compr Psychiatry 91:34-38.

https://doi.org/10.1016/j.comppsych.2019.03.004

35. Dell'Osso L, Cremone IM, Carpita B, Dell'Oste V, Muti D, Massimetti G, Barlati S, Vita A, Fagiolini A, Carmassi C, Gesi C (2019) Rumination, posttraumatic stress disorder, and mood symptoms in borderline personality disorder. Neuropsychiatr Dis Treat 15:1231-1238. https://doi.org/10.2147/NDT.S198616

36. Dell'Osso L, Carpita B, Bertelloni CA, Diadema E, Barberi FM, Gesi C, Carmassi C (2019) Subthreshold autism spectrum in bipolar disorder: prevalence and clinical correlates. Psychiatry Res 281:112605. https://doi.org/10.1016/j.psychres.2019.112605

37. Carpita B, Carmassi C, Calderoni S, Muti D, Muscarella A, Massimetti G, Cremone IM, Gesi C, Conti E, Muratori F, Dell'Osso L (2020) The broad autism phenotype in real-life: clinical and functional correlates of autism spectrum symptoms and rumination among parents of patients with autism spectrum disorder. CNS Spectr 25(6):765-773. https://doi.org/10.1017/S1092852919001615

38. Lai MC, Lombardo MV, Auyeung B, Chakrabarti B, Baron-Cohen S (2015) Sex/gender differences and autism: setting the scene for future research. J Am Acad Child Adolesc Psychiatry 54(1):11-24. https://doi.org/10.1016/j.jaac.2014.10.003

39. Dell'Osso L, Abelli M, Pini S, Carpita B, Carlini M, Mengali F, Tognetti R, Rivetti F, Massimetti G (2015) The influence of gender on social anxiety spectrum symptoms in a sample of university students. Riv Psichiatr 50(6):295-301. https://doi.org/10.1708/2098.22688

40. Dell'Osso L, Gesi C, Massimetti E, Cremone IM, Barbuti M, Maccariello G, Moroni I, Barlati S, Castellini G, Luciano M, Bossini L, Rocchetti M, Signorelli M, Aguglia E, Fagiolini A, Politi P, Ricca V, Vita A, Carmassi C, Maj M (2017) Adult Autism Subthreshold Spectrum (AdAS Spectrum): validation of a questionnaire 
investigating subthreshold autism spectrum. Compr Psychiatry 73:61-83.

https://doi.org/10.1016/j.comppsych.2016.11.001

41. Vannucchi G, Masi G, Toni C, Dell'Osso L, Erfurth A, Perugi G (2014) Bipolar disorder in adults with Asperger $\llbracket$ S Syndrome: a systematic review. J Affect Disord 168:151-160.

https://doi.org/10.1016/j.jad.2014.06.042

42. Dell'Osso L, Dalle Luche R, Maj M (2016) Adult autism spectrum as a transnosographic dimension. CNS Spectr 21(2):131-133. https://doi.org/10.1017/S1092852915000450

43. Dell'Osso L, Bertelloni CA, Di Paolo M, Avella MT, Carpita B, Gori F, Pompili M, Carmassi C (2019)

Problematic Internet Use in university students attending three superior graduate schools in Italy: is Autism Spectrum related to suicide risk? Int J Environ Res Public Health 16(7):1098.

https://doi.org/10.3390/ijerph16071098

44. Dell'Osso L, Carpita B, Cremone IM, Muti D, Diadema E, Barberi FM, Massimetti G, Brondino N, Petrosino B, Politi P, Aguglia E, Lorenzi P, Carmassi C, Gesi C (2019) The mediating effect of trauma and stressor related symptoms and ruminations on the relationship between autistic traits and mood spectrum. Psychiatry Res 279:123-129. https://doi.org/10.1016/j.psychres.2018.10.040

45. Carpita B, Muti D, Muscarella A, Dell'Oste V, Diadema E, Massimetti G, Signorelli MS, Fusar Poli L, Gesi C, Aguglia E, Politi P, Carmassi C, Dell'Osso L (2019) Sex differences in the relationship between PTSD Spectrum symptoms and autistic traits in a sample of university students. Clin Pract Epidemiol Ment Health 15:110-119. https://doi.org/10.2174/1745017901915010110

46. Donati MA, Berrocal C, Primi C, Petracchi G, Carpita B, Cosci F, Ruiz A, Carmassi C, Dell'Osso L (2019) Measuring subthreshold autistic traits in the general population: psychometric properties of the Adult Autism Subthreshold Spectrum (AdAS Spectrum) scale. Psychiatry Res 281:112576. https://doi.org/10.1016/j.psychres.2019.112576

47. Dell'Osso L, Carmassi C, Cremone IM, Muti D, Salerni A, Barberi FM, Massimetti E, Gesi C, Politi P, Aguglia E, Maj M, Carpita B (2020) Defining the optimal threshold scores for Adult Autism Subthreshold Spectrum (AdAS Spectrum) in clinical and general population. Clin Pract Epidemiol Ment Health 16:204-211. https://doi.org/10.2174/1745017902016010204

48. Luck-Sikorski C, Jung F, Schlosser K, Riedel-Heller SG (2019) Is orthorexic behavior common in the general public? A large representative study in Germany. Eat Weight Disord 24(2):267-273. https://doi.org/10.1007/s40519-018-0502-5

49. Arusoğlu G, Kabakçi E, Köksal G, Merdol TK (2008) Orthorexia nervosa and adaptation of ORTO-11 into Turkish. Turk Psikiyatri 19(3):283-291

50. Brytek-Matera A, Krupa M, Poggiogalle E, Donini LM (2014) Adaptation of the ORTHO-15 test to Polish women and men. Eat Weight Disord 19(1):69-76. https://doi.org/10.1007/s40519-014-0100-0

51. Dittfeld A, Gwizdek K, Jagielski P, Brzęk J, Ziora K (2017) A study on the relationship between orthorexia and vegetarianism using the BOT (Bratman Test for Orthorexia. Psychiatr Pol 51(6):1133-1144. https://doi.org/10.12740/PP/75739

52. Parra-Fernández ML, Manzaneque-Cañadillas M, Onieva-Zafra MD, Fernández-Martínez E, FernándezMuñoz JJ, Prado-Laguna M, Brytek-Matera A (2020) Pathological preoccupation with healthy eating 
(Orthorexia Nervosa) in a Spanish sample with vegetarian, vegan, and non-vegetarian dietary patterns. Nutrients 12(12):3907. https://doi.org/10.3390/nu12123907

53. Brytek-Matera A (2021) Vegetarian diet and orthorexia nervosa: a review of the literature. Eat Weight Disord 26(1):1-11. https://doi.org/10.1007/s40519-019-00816-3

54. Wentz E, Lacey JH, Waller G, Råstam M, Turk J, Gillberg C (2005) Childhood onset neuropsychiatric disorders in adult eating disorder patients. A pilot study. Eur Child Adolesc Psychiatry 14(8):431-437. https://doi.org/10.1007/s00787-005-0494-3

55. Oldershaw A, Treasure J, Hambrook D, Tchanturia K, Schmidt U (2011) Is anorexia nervosa a version of autism spectrum disorders? Eur Eat Disord Rev 9(6):462-474. https://doi.org/10.1002/erv.1069

56. Westwood H, Eisler I, Mandy W, Leppanen J, Treasure J, Tchanturia K (2016) Using the Autism-Spectrum Quotient to measure autistic traits in Anorexia Nervosa: a systematic review and meta-analysis. J Autism Dev Disord 46(3):964-977. https://doi.org/10.1007/s10803-015-2641-0

57. Dell'Osso L, Lorenzi P, Carpita B (2019) Autistic traits and illness trajectories. Clin Pract Epidemiol Ment Health 15:94-98. https://doi.org/10.2174/1745017901915010094

58. Mayes SD, Zickgraf H (2019) Atypical eating behaviors in children and adolescents with autism, ADHD, other disorders, and typical development. Res Autism Spectr Disord 64:76-83. https://doi.org/10.1016/j.rasd.2019.04.002

59. Gillberg C, Rastam M (1992) Do some cases of anorexia nervosa reflect underlying autistic-like conditions? Behav Neurol 5(1):27-32. https://doi.org/10.3233/BEN-1992-5105

\section{Figures}




\section{ORTO-R mean score}

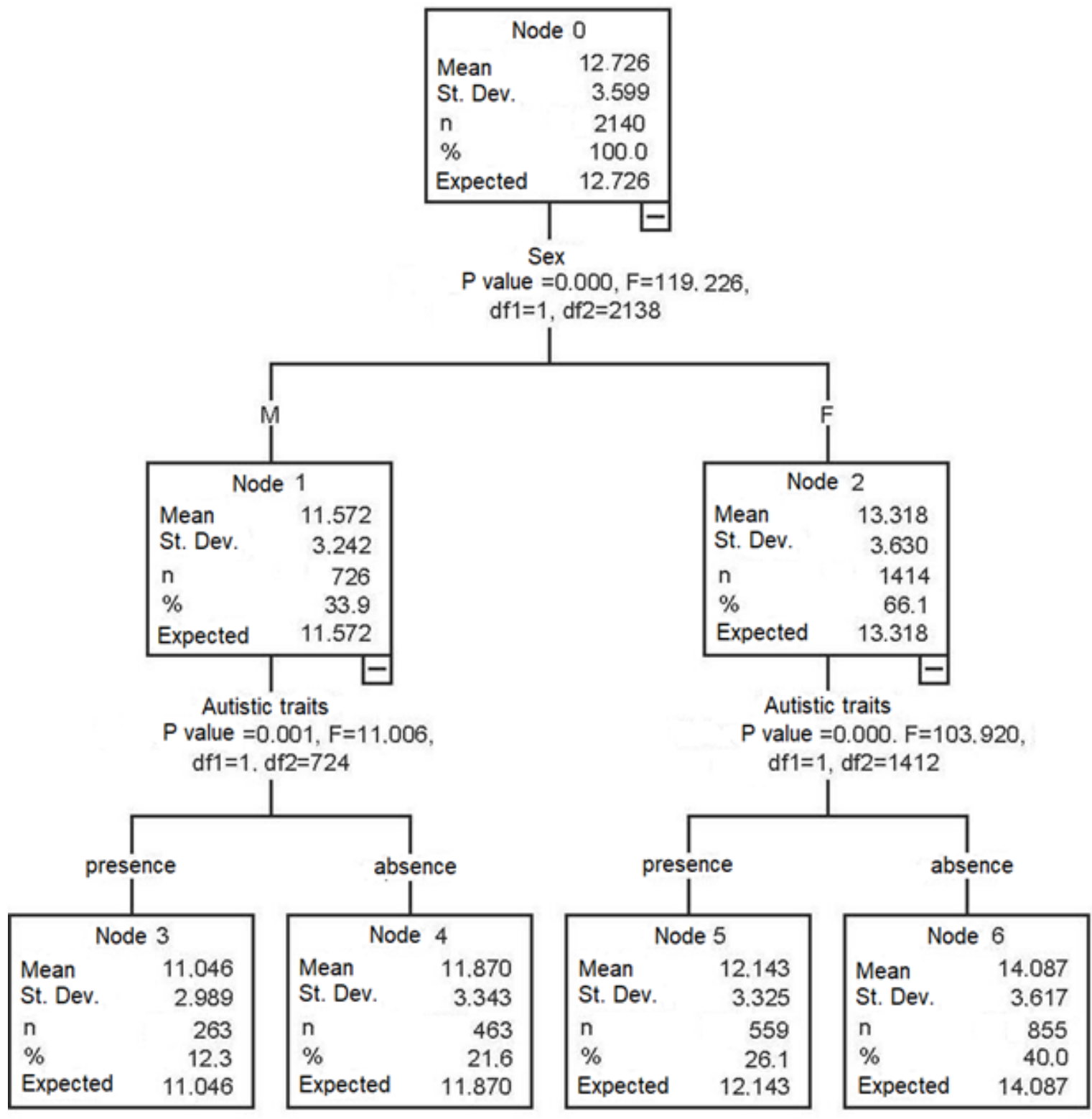

Figure 1

Tree decision model with ORTO-R score as independent variable and sex, type of diet and presence of AT as independent variables 


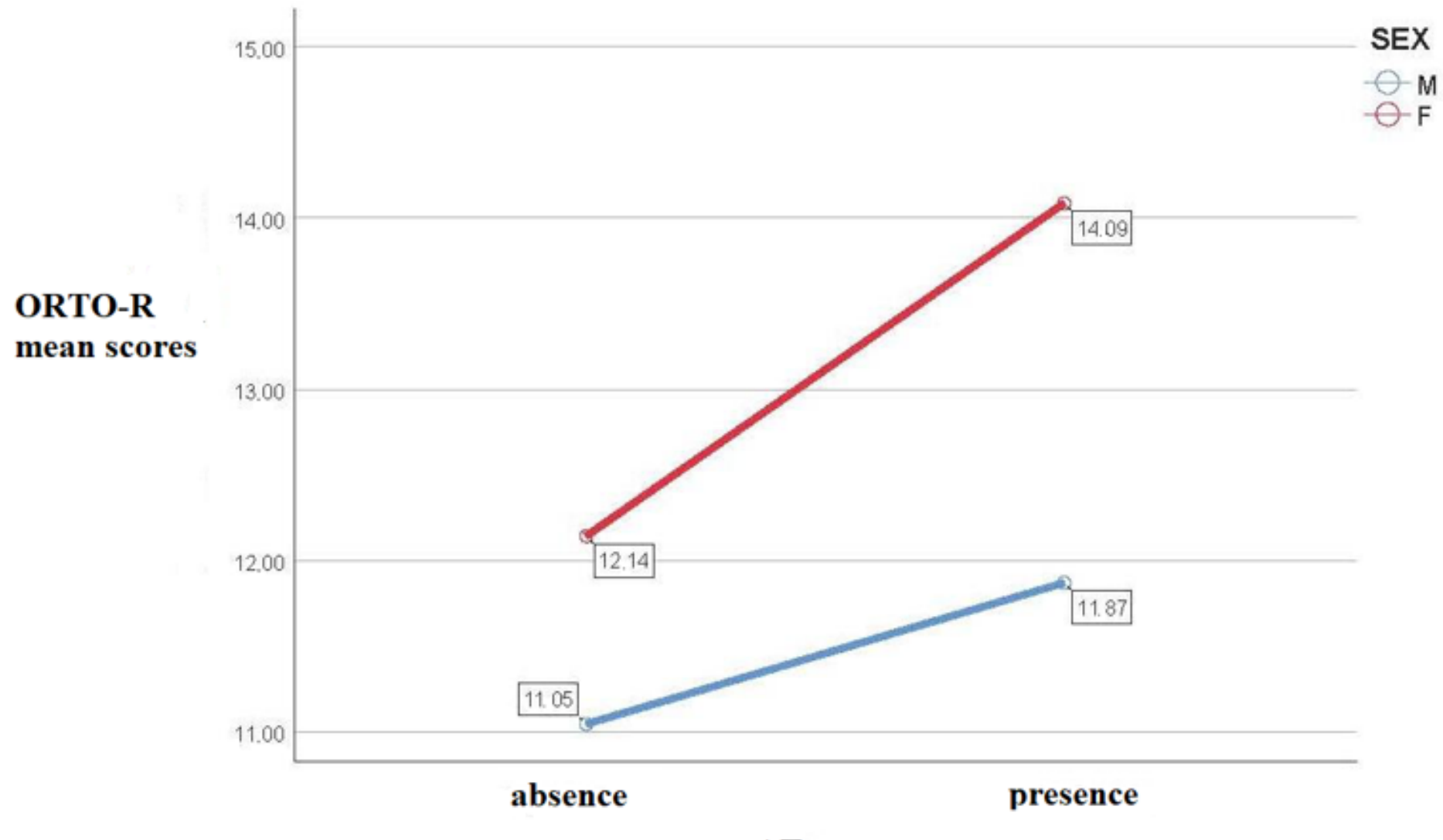

AT

Figure 2

Profile plot of estimated marginal means for ORTO-R depending from presence/absence of AT in males and females 